\title{
EXPERIMENTAÇÃO EM ESPAÇOS NÃO FORMAIS DE EDUCAÇÃO: O ENSINO DE CONCEITOS CIENTÍFICOS EM UM CENTRO DE EDUCAÇÃO AMBIENTAL
}

\section{Experimentation in Non-Formal Education Spaces: The Teaching of Scientific Concepts in An Environmental Education Center}

\author{
Vanessa Fonseca de Souza ${ }^{1}$ \\ André de Azambuja Maraschin ${ }^{2}$ \\ Ângela Maria Hartmann ${ }^{3}$ \\ Márcio Marques Martins ${ }^{4}$
}

\begin{abstract}
Resumo: O uso da experimentação tem sido considerado essencial no processo de ensino e aprendizagem, por despertar um forte interesse nos alunos. Levando em conta essa premissa, realizou-se uma pesquisa com o objetivo de avaliar como o desenvolvimento de experimentos demonstrativos em microescala e contextualizados em situações do cotidiano podem contribuir para a aprendizagem de conceitos científicos envolvidos no tratamento da água e, ao mesmo tempo, promover a reflexão dos visitantes em uma Estação de Tratamento de Água. O roteiro contemplou a abordagem dos conceitos de reação química, gravidade e separação de misturas. A pesquisa classifica-se como de natureza interpretativa, com análises qualitativa e quantitativa de questionários, respondidos por alunos do primeiro ano do Ensino Médio de duas escolas da rede pública estadual. Os resultados apontaram contribuições positivas à aprendizagem dos conceitos científicos e conscientização sobre o uso da água, trabalhados na visita e durante a experimentação demonstrativa. Argumentamos a favor do desenvolvimento de mais atividades nessa perspectiva, desde que sejam planejadas, considerando os objetivos de ensino e as especificidades de aprendizagem.
\end{abstract}

Palavras-chave: Estação de Tratamento de Água. Educação não formal. Ensino de ciências.

\footnotetext{
${ }^{1}$ Mestre em Ensino de Ciências e Especialista em Educação em Ciências (UNIPAMPA). Especialista em Gestão de Recursos Hídricos (UCPel). Bacharel em Ciências Biológicas (UFPel). Formada em Técnico em Química. Atualmente é Bióloga do Departamento de Água e Esgoto de Bagé-RS (DAEB) e atua como Diretora da ETA do DAEB. ORCID: https://orcid.org/0000-0003-0789-9656. E-mail: nessafsouza@ gmail.com.
}

2 Mestrando em Ensino e Licenciado em Química (UNIPAMPA). Especialista em Administração Escolar, Supervisão e Orientação e em Gestão Escolar (UNIASSELVI). Membro do Grupo de Estudos e Pesquisa em Inclusão e Diversidade na Educação Básica e no Ensino Superior (INCLUSIVE/UNIPAMPA) e do Grupo de Pesquisa sobre Aprendizagens, Metodologias e Avaliação (G.A.M.A/UNIPAMPA). ORCID: https://orcid.org/0000-0002-2153-8024. E-mail: andremaraschin@ hotmail.com.

\footnotetext{
${ }^{3}$ Doutora e Mestre em Educação (UnB). Licenciada em Matemática (Unisinos). Atualmente é professora associada da UNIPAMPA, docente do curso de Ciências Exatas - Licenciatura, campus Caçapava do Sul-RS, e do Programa de Pós-Graduação em Ensino de Ciências, campus Bagé-RS, Caçapava do Sul-RS e Dom Pedrito-RS. Coordenadora institucional do Programa Institucional de Bolsa de Iniciação à Docência - PIBID, CAPES 20202022. ORCID: https://orcid.org/0000-0002-4028-8577. E-mail: angelahartmann@unipampa.edu.br.

${ }^{4}$ Doutor em Química Teórica (UFRGS). Licenciado em Química (ULBRA). Bacharel em Química (UFRGS). Atualmente é professor do Mestrado Profissional em Ensino de Ciências (UNIPAMPA) e Coordenador do Núcleo de Química, Física e Matemática do Residência Pedagógica CAPES 2020/UNIPAMPA. ORCID: https://orcid.org/0000-0001-9117-7394. E-mail: marciomarques@ unipampa.edu.br.
} 


\begin{abstract}
The use of experimentation has been considered essential in the teaching and learning process, as it awakens a strong interest in students. Taking this premise into account, a research has been done with the objective of evaluating how the development of demonstrative experiments in microscale and contextualized in daily situations can contribute to the learning of scientific concepts related to the water treatment and, at the same time, promote the reflexion of visitors in a Water Treatment Station. The guide contemplated the Chemical reaction, gravity and THE separation of mixtures concepts. The research is classified as interpretative nature, with qualitative and quantitative analysis of questionnaires, answered by students in the first year of high school in two public schools in the STATE. The results show that there were positive contributions to the teaching of science in relation to the use of experiments in a non-formal educational space, as long as the action is achieved in a way that complements the teaching method given BY the school. The results showed positive contributions to the learning of scientific concepts and awareness about the water use, OBSERVED during the visitation and demonstrative experimentation. It has been argued in favor of the development of more activities in this perspective, as long as they are planned, considering the teaching objectives and the learning specificities.
\end{abstract}

Keywords: Water Treatment Plant. Non-formal education. Science teaching.

\title{
10 lugar de encontro e o início da pesquisa
}

Assumimos como lugar de fala, o encontro entre os autores, no curso de Licenciatura em Química e no Programa de Pós-Graduação em Ensino de Ciências (PPGEC), da Universidade Federal do Pampa (UNIPAMPA). A proposta dessa escrita surge em período prépandêmico, inspirada na dissertação de mestrado da autora 1, que por formação é bióloga e trabalha como educadora ambiental em um Centro de Educação Ambiental (CEA) localizado em uma Estação de Tratamento de Água (ETA). Ao longo dos anos, a referida autora constatou a necessidade de aproveitar melhor o espaço oferecido pelo CEA, reconhecendo-o como um espaço não formal de educação (ENFE) para o Ensino de Ciências (EC), por receber visitantes de diferentes grupos e faixas etárias, incluindo estudantes da Educação Básica.

O CEA pertence ao Departamento de Água e Esgotos do município de Bagé, RS (DAEB), e fica localizado no pátio da ETA. Funciona desde o ano de 2007, com o intuito de realizar projetos e ações voltados à educação ambiental, como é o exemplo do projeto Sala Verde Conscientizar, aprovado por meio de edital do Ministério do Meio Ambiente, em 2006. A Sala Verde possui uma biblioteca com obras socioambientais, com aproximadamente 800 itens para consulta da comunidade e um auditório para 50 pessoas, equipado com data show, televisão e DVD. Antes do período de pandemia, causada pela COVID-19, o espaço recebia cerca de 2.000 mil pessoas por ano. As atividades são organizadas de acordo com os objetivos do grupo visitante, podendo variar entre palestras, exibições de filmes, jogos, trilhas de identificação de árvores e visitação na ETA. No geral, independente dos objetivos do grupo que se faz presente nas visitações, é relatada a história da captação de água no município, a forma como seu tratamento é feito e, também, descrita sua trajetória até as residências.

Diante desse contexto, em virtude das constatações da autora 1 sobre melhor aproveitar o espaço oferecido pelo CEA enquanto um ENFE, algumas inquietações começaram a emergir, tais como: desarticulação entre as atividades realizadas e as possíveis relações com temas do cotidiano ligados à ciência e tecnologia; potencial das atividades para o EC na formação de 
alunos da Educação Básica; e o nível de abstração exigido para compreensão de algumas etapas do tratamento da água. Na tentativa de buscar soluções para tais inquietações, considerou-se a possibilidade de utilizar a experimentação como recurso pedagógico mediador do processo de ensino e aprendizagem durante visitações de estudantes à ETA. Com objetivo de avaliar como a realização dos experimentos demonstrativos em microescala e contextualizados em situações do cotidiano, podem contribuir para a aprendizagem de conceitos científicos envolvidos no tratamento da água e, ao mesmo tempo, promover a reflexão dos visitantes, adotou-se como questão de pesquisa: "Como a experimentação em um espaço não formal de educação pode contribuir para a aprendizagem de conceitos científicos pertinentes ao tratamento da água?"

A realização da ação e da pesquisa se justificam pela exigência da sociedade atual de ampliação de oferta de espaços de formação científica e de realização de atividades pedagógicas diversificadas, nos diferentes níveis de ensino, incluindo atividades de campo, que deslocam os estudantes a outros espaços, fora da escola (VIVEIRO; DINIZ, 2009). Entende-se que o CEA, enquanto ENFE, pode oferecer possibilidades de práticas pedagógicas que articulem o conhecimento científico ao cotidiano dos alunos, constituindo-se em um espaço de experiências motivadoras por conta de características próprias, diferentes das padronizações encontradas nos ambientes escolares.

A partir de estudos sobre a temática escolhida, resgatam-se, a seguir, alguns autores que sustentaram teoricamente a ação pedagógica e a pesquisa. Tais autores discutem os ENFE, o ensino de ciências e a experimentação, a experimentação em ENFE e os conceitos científicos de reações químicas, gravidade e processos de separação de misturas.

\section{Os espaços não formais de educação}

Partindo do entendimento de que existe construção do conhecimento fora do espaço escolar, há necessidade de distinguir esses espaços, categorizando as práticas em educação neles realizadas. Marques e Freitas (2017) identificaram em sua pesquisa que, na literatura nacional, a maior parte dos autores opta por utilizar a terminologia referente a três grupos de espaços: 'formal', que se apresenta descontextualizada e padronizada na linguagem e no simbólico; 'não formal', que permite maior abertura na escolha de conteúdos e metodologias dadas as necessidades do ambiente; e 'informal', associada ao nosso cotidiano.

Logo, a educação formal é aquela realizada dentro do sistema escolar. Já a educação não formal abrange qualquer atividade educacional organizada e estruturada de forma intencional, que não corresponda exatamente ao que se estabelece nos currículos para a educação formal. A terceira denominação de prática educativa, a informal, contempla um processo educativo sem planejamento, mediado pela influência da família, do ambiente de trabalho, pela mídia, espaços de lazer, entre outros, que possibilitam a aprendizagem de valores e conhecimentos. Tais definições corroboram com a descrição de Hartmann (2012) para a distinção dos termos, pois deve-se levar em consideração o espaço em que ocorrem, a sua duração, o perfil do público e a intenção com que são realizadas. Marques e Freitas (2017) também consideram que os termos podem ser divididos em setores e dimensões, percebendo a educação não formal como um campo polissêmico, sem consenso sobre seu uso e definições.

Diante disso, cabe sinalizar a concepção de educação não formal adotada durante o percurso dessa pesquisa, a qual assumimos como práticas educacionais que ocorrem de maneira organizada dentro ou fora do espaço da escola e que têm como objetivo complementar a educação formal realizada com qualquer público. Nos ENFE, podem ser usadas metodologias que ajudam o aluno a construir seu conhecimento de forma lúdica, participativa e criativa, 
permitindo uma maior interação entre os participantes. Nesse caso, no CEA, a interação acontece entre alunos, professores e guias da visitação, extrapolando os limites da escola.

Tais argumentos vão ao encontro do que dizem Vieira, Bianconi e Dias (2005), que os centros de ciências estimulam a curiosidade dos visitantes, pois podem contemplar algumas carências da escola, como a falta de laboratórios e recursos audiovisuais que poderiam estimular o aprendizado. Silva e Vasconcelos (2013) defendem que o uso de didáticas e metodologias alternativas, a partir de atividades práticas, facilita a compreensão dos conteúdos de Ciências e Química e não precisam ocorrer necessariamente em laboratórios, tendo como possibilidade as visitações em locais como, por exemplo, uma ETA. Nesse sentido, atividades didáticas que abordem os aspectos científicos do tratamento da água em ENFE, como acontece em uma ETA, podem levar a uma aprendizagem de Ciências que conecta aspectos científicos e tecnológicos à realidade dos estudantes. A seguir, serão apresentadas reflexões sobre tais aspectos.

\section{Ensino de ciências e a experimentação demonstrativa}

O trabalho experimental nas escolas tem sua origem há mais de cem anos, inspirado nas atividades desenvolvidas nas universidades, com o objetivo de permitir que os educandos aprendam conteúdos científicos e saibam aplicá-los (GALIAZZI et al., 2001). Logo, ao cumprir com esse objetivo, a experimentação ganha espaço nas discussões sobre práticas pedagógicas, pois de acordo com Francisco Junior, Ferreira e Hartwig (2008) e Salesse (2012), ela motiva os alunos no processo de ensino e aprendizagem, proporcionando a evolução do vocabulário de termos conceituais, estimulando a participação nas atividades, e sobretudo, atingindo muitos objetivos de aprendizagem. Santos e Menezes (2020) corroboram com esses argumentos, considerando a experimentação como um recurso de fácil inclusão na prática pedagógica, atraindo a atenção dos estudantes e aproximando-os das práticas científicas.

No que se refere à ação pedagógica descrita neste artigo, assume-se a experimentação do tipo demonstrativa. Alguns autores apresentam concepções a respeito desse tipo de experimentação, por exemplo, Francisco Junior, Ferreira e Hartwig (2008), Zômpero, Passos e Carvalho (2012), Santos e Maldaner (2011), Santos e Menezes (2020) e Gaspar e Monteiro (2005). Na opinião de Francisco Junior, Ferreira e Hartwig (2008), a experimentação demonstrativa geralmente é mais fácil de ser conduzida e os alunos tendem a assumir um papel passivo. Em outras palavras, ela contribui com a explicação dos conteúdos, mas estão presentes nela os riscos da memorização e da reprodução. Zômpero, Passos e Carvalho (2012), entendem que essa atividade pode ser introduzida aos discentes de forma equivocada, pois possui caráter meramente ilustrativo e segue os passos da escola tradicional. No entanto, apontam três pontos positivos que podem ser atingidos quando a experimentação demonstrativa é bem planejada: melhor interpretação das informações em relação ao conhecimento científico; interação social e curiosidade sobre situações variadas; e maior vontade de participação nas aulas.

Assim, se as atividades experimentais demonstrativas atingirem os três pontos destacados, permitindo a criação de significados diante dos conteúdos e respostas formuladas a partir de argumentos, terão cumprido seu propósito para além dos modelos de educação que tendem a ser mais tradicionais. Nas palavras de Zômpero, Passos e Carvalho (2012, p. 46), é necessário "que o professor problematize a situação e não apenas mostre aos alunos o que vai ocorrer". Santos e Maldaner (2011), por sua vez, indicam que as atividades experimentais demonstrativas nem sempre acontecem em laboratórios, podendo ocorrer em ambientes alternativos, incluindo locais fora da escola. 
Santos e Menezes (2020, p. 190-191), respaldados em diversos autores, indicam a abordagem experimental demonstrativa quando não é possível a realização dos experimentos "por todos os alunos, seja por falta de recursos, materiais ou estrutural, ou casos em que o professor não dispõe do tempo necessário para que todos participem da prática". Gaspar e Monteiro (2005) defendem que esse tipo de experimentação favorece a interação social, criando ambientes de aprendizagem que, consequentemente, instigarão o questionamento, a formulação de hipóteses e as respostas por parte dos estudantes. Os autores apontam ainda, que após práticas experimentais demonstrativas, os alunos melhoram seu vocabulário científico e apresentam interesse pela área de estudo, ressaltando a importância do planejamento da ação pelo docente.

Zômpero, Passos e Carvalho (2012, p. 45) destacam a responsabilidade que recai sobre o professor, afirmando que "as atividades práticas podem ser desenvolvidas além dos limites do laboratório didático e também realizadas com materiais alternativos, sendo que o sucesso do experimento depende do planejamento e do bom preparo do professor". Em vista disso, havendo planejamento, considera-se que há possibilidades de articular atividades experimentais aos ENFE. O próximo tópico apresenta trabalhos que realizaram tal articulação.

\section{Experimentação em espaços não formais de educação}

A atividade de experimentação apresentada neste artigo se aproxima de estudos de outros autores, como é o caso de Pinto e Figueiredo (2010), que apresentaram sua proposta baseada no EC em Centros de Ciências de Duque de Caxias-RJ, utilizando a experimentação. Dentre seus achados, é possível citar a falta de valorização desses espaços, a contribuição dos ENFE para a geração de conhecimento e aperfeiçoamento das aulas, e por fim, a aposta da experimentação como ferramenta que é capaz de trazer questionamentos, reflexões e interesse aos alunos. Já o trabalho de Porto et al. (2011) traz um estudo sobre o ensino de conceitos químicos e físicos em ENFE, mostrando que o EC nesses espaços conduz os sujeitos ao aprendizado de conceitos científicos importantes para explicar situações do cotidiano.

No mesmo ano, Perticarrari, Trigo e Barbieri (2011) publicaram uma atividade realizada com alunos da Educação Básica que participavam de programas da Casa da Ciência do Hemocentro de Ribeirão Preto, SP. Nessa atividade, as investigações focaram-se no ensino de biologia a partir de experimentos investigativos no campo da botânica e os autores destacaram possibilidades de desenvolver atividades laboratoriais que quase sempre não são comuns nas escolas públicas. Bertan et al. (2015) desenvolveram oficinas para alunos do ensino médio (EM) na Casa Familiar Rural de Dois Vizinhos, PR, objetivando popularizar o ensino de bioquímica através de aulas expositivas e oficinas de experimentação sobre tópicos básicos relacionados ao dia a dia dos estudantes. Destaca-se que, como não havia laboratório para as atividades, elas foram realizadas no refeitório da instituição.

Cleophas (2016) apresenta discussões de um grupo de estudantes de licenciatura em Ciências da Natureza a partir de uma aula realizada durante visita guiada ao arquipélago Delta do Parnaíba, PI, buscando trabalhar de forma contextualizada e interdisciplinar os conteúdos ministrados em um componente curricular. A autora entende que essas atividades permitem aos alunos colocar em prática os conhecimentos adquiridos em situações-problemas que geram reflexão e discussões teórico-práticas. Também no referido ano, Foleis et al. (2016) propuseram algumas oficinas com alunos do EM da rede pública de ensino de São Paulo, SP, voltadas para o tratamento de água e processos físico-químicos, na intenção de contextualizar o ensino de Química a partir de estratégias envolvendo Ciência, Tecnologia e Sociedade (CTS). Os autores apostaram na experimentação por acreditarem que, por meio dela, o discente consegue se 
aproximar dos conceitos químicos e suas aplicações, desenvolver atitudes fundamentadas no conhecimento científico e assumir um papel mais ativo na sua aprendizagem.

Outro trabalho, realizado por Santos e Amaral (2019), baseado na crise hídrica que o Brasil sofreu em 2015, objetivou aplicar uma sequência didática com alunos do segundo ano do EM, envolvendo a construção parcial de uma ETA. Como pontos positivos, os autores destacaram as interações interpessoais na aquisição de conhecimento, seja ele técnico ou social. Por fim, Rocha e Malheiro (2018) e Barbosa, Rocha e Malheiro (2019) apresentam etapas de um projeto, envolvendo experimentação investigativa em um Clube de Ciências, no qual classificaram e organizaram manifestações/perguntas durante as atividades como estratégia na condução de investigações e mediação do conhecimento.

\section{Os conceitos científicos abordados na ação pedagógica}

\subsection{Reação Química}

O conceito de reação química tem sido apontado como problemático para o ensino e a aprendizagem. Mendes (2011), em sua dissertação de mestrado sobre a abordagem do conceito de reações químicas no Ensino Médio, concluiu que o problema de aprendizagem deste conceito decorre das incompreensões nas interpretações macroscópica e/ou microscópicas e ao nível de abstração que alguns conceitos relacionados exigem. Macedo e Penha (2014) investigaram o perfil conceitual sobre reações químicas de 65 alunos dos $2^{\circ}$ anos dos cursos técnico integrados em Eletrotécnica, Informática e Química do Instituto Federal de Rondônia, Campus Porto Velho Calama. O tratamento dos dados se deu pela divisão das respostas em três categorias.

A primeira categoria, denominada 'Reação Química = Mistura de substâncias', agrupou as respostas dos estudantes que classificaram reações químicas a partir da homogeneidade entre as substâncias, demonstrando equívocos conceituais que envolvem transformações dos estados físicos da matéria. A segunda categoria, denominada 'Conceito sintético x Macroscópico (Organoléptico)', agrupou as respostas que consideraram qualquer mudança visual ou alteração nas características organolépticas como uma reação química. A terceira e última categoria, denominada 'Conceito macroscópico x Conceito Microscópico', agrupou as concepções dos estudantes que consideraram que em reações químicas há alterações microscópicas relacionadas ao rearranjo dos átomos, conforme os modelos atômicos.

Nesta produção, levando em consideração o processo de tratamento da água, optou-se pela utilização da segunda categoria apontada por Macedo e Penha (2014), definindo reação química como um processo no qual duas ou mais substâncias (reagentes) se transformam em outras substâncias novas (produtos), podendo ser identificadas pelos sentidos (características organolépticas). Na ETA, um exemplo de reação química ocorre no processo de floculação, que consiste basicamente em aglomerar as partículas de sujeira de forma que seu volume e peso aumentem, permitindo a ação da gravidade.

\subsection{Gravidade}

De acordo com a mecânica newtoniana, a gravidade é uma força que atua entre corpos massivos. Isaac Newton, ao analisar o movimento da Lua ao redor da Terra, percebeu que havia uma força de atração entre a Terra e a Lua e demonstrou que existe uma força de atração entre o Sol e os planetas. Concluiu que "esta atração deve ser um fenômeno geral (universal) e deve se manifestar entre dois objetos materiais quaisquer" (MÁXIMO; ALVARENGA, 2003, p. 213), denominando-a como a Lei da Gravitação Universal. 
A força de atração gravitacional, ou gravidade, depende da quantidade de matéria que existe nos corpos. A Terra possui uma grande quantidade de matéria e produz uma grande atração aos corpos que interage. Os corpos sobre a Terra possuem uma quantidade de matéria relativamente pequena e, por isso, não parecem atraí-la com uma força de mesma intensidade. No entanto, essa força de atração dos objetos sobre a Terra possuem a mesma intensidade da força que a Terra exerce sobre esses objetos (Par ação/reação - $3^{a}$ Lei de Newton). Apenas observamos o movimento do objeto indo ao encontro da Terra devido à massa da Terra ser muito grande e possuir muita inércia. Newton sustentou que todos os corpos do universo se atraem mutuamente. Além disso, a força gravitacional é sempre atrativa. Não existe o que se poderia chamar de força gravitacional repulsiva (HALLIDAY; RESNICK; WALKER, 2016).

\subsection{Separação de misturas (floculação, decantação e filtração)}

Entende-se como floculação, a aglutinação das partículas de um precipitado ou de um sistema coloidal (COMPANHIA RIOGRANDENSE DE SANEAMENTO, 2021), frequentemente ocasionada pela alteração do $\mathrm{pH}$ do sistema. A água das hidráulicas é purificada pela floculação ao receber a substância química sulfato de alumínio $\left(\mathrm{Al}_{2} \mathrm{SO}_{4}\right)$, que promove a aglutinação das impurezas e forma flocos que serão facilmente removidos (DI BERNARDO; PAZ, 2008). De acordo com Fonseca (2016), a floculação separa da água as impurezas de natureza coloidal pela adição de coagulantes químicos (óxido de cálcio ou sulfato de alumínio), que promovem a aglutinação das partículas em suspensão, facilitando sua deposição sob a forma de flocos.

$\mathrm{Na}$ decantação ocorre a separação, por gravidade, de impurezas sólidas que estão contidas na mistura (DI BERNARDO; PAZ, 2008). Essa separação acontece pela sedimentação dos flocos de sujeira no decantador (COMPANHIA RIOGRANDENSE DE SANEAMENTO, 2021), já que são mais pesados do que a água, caindo para o fundo. Segundo Fonseca (2016), a decantação serve para separar a água dos focos de impurezas formados na etapa de floculação.

Por fim, a filtração retém os flocos menores que não foram separados na etapa de decantação (COMPANHIA RIOGRANDENSE DE SANEAMENTO, 2021). É um processo de separação de mistura sólido-líquido (DI BERNARDO; PAZ, 2008). Nele, mais uma vez a ação da gravidade atua, pois quando a água passa pelas camadas filtrantes, sua massa contendo impurezas é admitida pela parte superior do filtro (que possui maior potencial gravitacional) e, lenta e continuamente, é atraída para o solo (menor potencial gravitacional). Durante esse movimento, do alto do filtro para baixo, as impurezas vão ficando retidas nos poros das camadas filtrantes (quanto mais no alto, maiores os poros e quanto mais abaixo, menores os poros). Cabe destacar que o filtro é posicionado abaixo dos tanques de decantação, de forma que a água a ser filtrada possa ser movimentada apenas pela ação da força gravitacional, ou seja, sem gerar custos adicionais no tratamento.

Novamente, destaca-se que as etapas acima dependem de processos químicos e físicos. $\mathrm{Na}$ floculação temos um exemplo de reação química, já na decantação e filtração temos o conceito de gravidade. Na próxima sessão os caminhos metodológicos serão apresentados.

\section{Caminhos metodológicos}

A pesquisa configura-se como de natureza interpretativa, uma vez que ela permite, dependendo do tipo de dados gerados, adotar para a análise tanto uma abordagem qualitativa quanto quantitativa. Segundo Moreira (2011), esse tipo de pesquisa busca identificar e 
compreender os significados que as pessoas atribuem às suas ações e às interações sociais que acontecem no contexto social. Para a obtenção de dados, foram utilizados instrumentos de pesquisa do tipo questionários, para avaliar o recurso didático utilizado e o aprendizado dos conceitos selecionados, além de registros gravados e filmados com autorização por escrito dos responsáveis pelos estudantes participantes. O questionário é uma ferramenta bastante utilizada para reunir dados, obtidos a partir de respostas às questões pelo próprio participante (CERVO; BERVIAN; SILVA, 2007). Os questionários podem conter perguntas abertas, permitindo respostas livres ou perguntas fechadas, que podem sugerir alternativas (MOREIRA, 2011). A análise dos dados foi de natureza quali-quantitativa, conforme descrito na sequência.

Foram utilizados dois questionários, denominados de pré-teste e pós-teste. O primeiro (pré-teste) contou com perguntas abertas e fechadas, objetivando realizar uma sondagem inicial sobre os conhecimentos dos estudantes relativos aos conceitos que seriam trabalhados. $\mathrm{O}$ segundo (pós-teste) contou também com perguntas abertas e fechadas, buscando comparar os resultados obtidos com as respostas dadas anteriormente. Os sujeitos participantes foram alunos de duas turmas do primeiro ano do EM, de duas escolas da rede pública. A escolha se deu devido a facilidade de transporte dos discentes até a ETA e pela proximidade da autora $1 \mathrm{com}$ os professores dessas turmas. A decisão por duas escolas se justifica pela possibilidade de aumentar a amostragem, levando em consideração as diferentes realidades. O primeiro ano do EM foi escolhido porque é nele que os conceitos escolhidos são usualmente trabalhados.

Cabe destacar que foi feito um contato prévio com as duas escolas e, após o aceite, seus representantes assinaram um termo de autorização para o desenvolvimento das atividades. Nele, continham a apresentação do projeto, os objetivos e as ações previstas. Para preservar a identidade das instituições, elas serão identificadas daqui em diante como E1 e E2. Os alunos participantes ou seus responsáveis assinaram um Termo de Consentimento Livre e Esclarecido, que também apresentava as informações iniciais do projeto, incluindo a realização de registros gravados em áudio, fotográficos e em vídeo, ratificando o sigilo dos dados informados. Reforçase que a pesquisa aconteceu antes da pandemia por COVID-19, mais precisamente no ano de 2015, em que a Resolução $N^{\circ}$ 510, de sete de abril de 2016 ainda não existia. Outrossim, a Universidade não exigia aprovação do projeto via Comitê de Ética em Pesquisa. Contudo, como pode ser observado, todos os cuidados quanto à ética na pesquisa foram adotados, a fim de proteger as identidades dos participantes e escolas envolvidos na aplicação.

A E1 é composta por cerca de 82 professores e 1.187 alunos. Localizada no centro da cidade, a escola atende apenas turmas de EM regular. A situação socioeconômica dos estudantes é considerada diversificada. Os dados fornecidos pelo Serviço de Orientação Educacional (SOE), mostram que a maior parte dos pais concluiu os níveis fundamental e médio e que a renda familiar varia entre dois e cinco salários-mínimos. A turma participante era composta por 27 discentes matriculados, com 22 frequentando normalmente as aulas.

A E2 possui uma comunidade escolar com cerca de 70 professores e 1.400 alunos. Fica localizada no centro da cidade, atendendo turmas de Ensino Fundamental, EM politécnico e a modalidade de Educação de Jovens e Adultos (EJA). A renda familiar varia de um a três salários-mínimos. A turma participante era formada por 30 alunos.

\subsection{Organização dos três momentos de pesquisa}

A atividade se dividiu em três momentos: $1^{\circ}$ - Sensibilização inicial com sondagem, através da aplicação do pré-teste; $2^{\circ}$ - Visita à ETA e desenvolvimento da experimentação; e $3^{\circ}$ - Aplicação do pós-teste e problematização final. Através dessa estratégia de pesquisa, pôde-se 
examinar as concepções dos sujeitos sobre o tema e buscar evidências de uma mudança comportamental no que diz respeito à compreensão e aplicação dos conhecimentos, bem como conscientização sobre o uso da água. Em outras palavras, houve a pretensão de interpretar a mudança de atitude dos alunos e como eles formalizam os conceitos científicos após participar da ação pedagógica de experimentação. Para organizar os três momentos da pesquisa, foi elaborado o Quadro 1. Nele estão delimitados os objetivos de ensino e de aprendizagem e são definidas as ações para atingi-los:

Quadro 1 - Organização prévia das atividades

\begin{tabular}{|c|c|c|c|}
\hline Momento & Objetivos de ensino & $\begin{array}{c}\text { Objetivos de } \\
\text { aprendizagem }\end{array}$ & Ações \\
\hline $\begin{array}{c}1^{\circ} \\
\text { Sensibilização inicial } \\
\text { e aplicação do pré- } \\
\text { teste }\end{array}$ & $\begin{array}{l}\text { - Apresentar os conceitos } \\
\text { científicos referentes ao } \\
\text { tratamento da água. }\end{array}$ & $\begin{array}{l}\text { - Estabelecer ligações entre } \\
\text { os conceitos científicos e o } \\
\text { tratamento da água. }\end{array}$ & $\begin{array}{l}\text { - Aplicação de } \\
\text { questionário (pré-teste) e } \\
\text { diálogo sobre as } \\
\text { respostas. }\end{array}$ \\
\hline $\begin{array}{c}2^{\circ} \\
\text { Visita à ETA e } \\
\text { experimentação }\end{array}$ & $\begin{array}{l}\text { - Apresentar os processos } \\
\text { do tratamento da água e os } \\
\text { fenômenos físicos e } \\
\text { químicos presentes; } \\
\text { - Discutir o tratamento da } \\
\text { água em macroescala e em } \\
\text { um modelo representativo } \\
\text { em microescala. }\end{array}$ & $\begin{array}{l}\text { - Compreender os } \\
\text { conceitos científicos } \\
\text { presentes no tratamento da } \\
\text { água em uma ETA; } \\
\text { - Compreender as etapas } \\
\text { do tratamento da água } \\
\text { (macroescala) reproduzidas } \\
\text { na experimentação } \\
\text { demonstrativa } \\
\text { (microescala). }\end{array}$ & $\begin{array}{l}\text { - Realizar visita guiada } \\
\text { na ETA do município; } \\
\text { - Realizar experimentos } \\
\text { demonstrativos de } \\
\text { floculação, decantação e } \\
\text { filtração, comparando-os } \\
\text { com as etapas da visita. }\end{array}$ \\
\hline $\begin{array}{c}3^{\mathbf{o}} \\
\text { Pós-teste } \\
\text { (problematização) }\end{array}$ & $\begin{array}{l}\text { - Promover a } \\
\text { (re)significação dos } \\
\text { conceitos científicos que } \\
\text { explicam o tratamento da } \\
\text { água. } \\
\text { - Promover mudanças } \\
\text { atitudinais com relação ao } \\
\text { uso da água. }\end{array}$ & $\begin{array}{l}\text { - Ressignificar os } \\
\text { conhecimentos apreendidos } \\
\text { durante a visitação à ETA; } \\
\text { - Refletir sobre a } \\
\text { necessidade de realizar } \\
\text { mudanças atitudinais com } \\
\text { relação ao uso da água. }\end{array}$ & $\begin{array}{l}\text { - Aplicação de } \\
\text { questionário (pós-teste); } \\
\text { - Comparação de } \\
\text { respostas do pré e pós- } \\
\text { teste; } \\
\text { - Diálogo sobre o } \\
\text { consumo de água e as } \\
\text { atitudes necessárias para } \\
\text { um uso racional da água. }\end{array}$ \\
\hline
\end{tabular}

Fonte: Elaborado pelos autores (2021).

No primeiro momento, foi realizada uma sondagem dos conhecimentos dos estudantes, abrindo caminhos para o planejamento da visitação. A visitação à ETA, no segundo momento, teve por finalidade apresentar novos detalhes sobre o tratamento da água, buscando reforçar a compreensão dos alunos sobre os conceitos científicos empregados para explicá-lo. A experimentação demonstrativa oportunizou a reprodução das etapas de tratamento em menor escala, tornando-as mais visíveis e distanciando os alunos de algumas dificuldades impostas pelo nível de abstração exigido por alguns conceitos. No terceiro momento, além de discussões a respeito do uso da água, ocorreu a problematização, que objetivou aproximar os conceitos espontâneos dos conceitos científicos. A seguir, detalha-se a montagem dos experimentos.

\subsection{Montagem dos experimentos}

A experimentação demonstrativa foi escolhida por dois fatores: o espaço disponível no CEA e o tempo de 45 minutos reservado para essa etapa durante a visita. É importante destacar que as duas turmas realizaram a visitação em momentos distintos e que, apesar de 
demonstrativa, a experimentação pode ser realizada também em uma sala de aula. Esse tipo de experimentação favoreceu a interação entre todos, pois, mesmo cada turma tendo sido organizada em um grupo único, os alunos tiveram acesso aos experimentos. Caso a turma seja organizada em mais grupos, sugere-se que estes sejam de no máximo quatro pessoas.

Foram realizados três experimentos relacionados entre si e a partir dos quais era possível discutir os conceitos de reação química, gravidade e a separação de misturas pela floculação, decantação e filtração. O primeiro experimento pode ser feito com materiais de fácil aquisição e consiste na representação de uma bacia hidrográfica, utilizando os seguintes materiais: um galão de cinco litros, areia fina, areia grossa, pedras, faca, pá pequena, copo plástico e tijolo vegetal. A descrição dos passos para construção se encontra no Quadro 2:

Quadro 2 - Passos para construção do primeiro experimento

\begin{tabular}{|l|l|}
\hline \multicolumn{1}{|c|}{ Descrição das etapas } & Ilustração \\
\hline 1. Cortar um retângulo no centro do galão com tampa e \\
sem rótulo;
\end{tabular}

Fonte: Elaborado pelos autores (2021).

O Quadro 2 representa uma bacia hidrográfica ou manancial de onde a água é captada, seja ele um rio, um lago ou uma barragem. Depois de confeccionada, joga-se água na parte verde de cobertura vegetal, representando a chuva. A captação acontecerá no copo que está na região central do galão. Essa água chegará suja ao recipiente (como as captações realizadas pela ETA). Passa-se ao segundo experimento, que necessita de alguns reagentes químicos. Como se sugere a realização do experimento em uma ETA, considera-se que esses materiais são de fácil aquisição. São eles: um béquer de $250 \mathrm{~mL}$, um balão volumétrico de $100 \mathrm{~mL}$ e uma pipeta de 5 mL. A descrição dos passos para construção se encontra no Quadro 3: 
Quadro 3 - Passos para construção do segundo experimento

\begin{tabular}{|l|}
\hline \multicolumn{1}{|c|}{ Descrição das etapas } \\
\hline 1. Dissolver $5 \mathrm{~g} \mathrm{de} \mathrm{Al}_{2} \mathrm{SO}_{4}$ em $50 \mathrm{~mL}$ de água usando o balão \\
volumétrico. Completar com água até os $100 \mathrm{~mL}$; \\
2. Colocar a água coletada na bacia hidrográfica no béquer. \\
Adicionar $10 \mathrm{~mL}$ da solução de $\mathrm{Al}_{2} \mathrm{SO}_{4}$ e mexer lentamente por \\
10 minutos. Aguardar a formação dos flocos (floculação); \\
3. Deixar o béquer em repouso para que os flocos decantem \\
(decantação).
\end{tabular}

Fonte: Elaborado pelos autores (2021).

O Quadro 3 apresenta o segundo experimento, após a captação da água. O primeiro processo de separação de misturas que ocorre é a floculação, no qual, após a adição de um agente químico (sulfato de alumínio), acontece uma reação química em que as partículas de sujeira se aglomeram. Agora, com volume e peso maiores, a ação da gravidade se torna mais rápida e evidente. $\mathrm{O}$ segundo processo de separação, a decantação, consiste na deposição dessas partículas maiores no fundo do recipiente, assim que a mistura repousa. Passa-se, então, ao terceiro e último experimento, que assim como o primeiro, utiliza materiais de fácil aquisição. São utilizados: uma garrafa PET de 600mL, tesoura, faca, areia fina, areia grossa, algodão, carvão e pedras. O Quadro 4 apresentará os passos para construção desse experimento:

Quadro 4 - Passos para construção do terceiro experimento

\begin{tabular}{|l|l|}
\hline \multicolumn{2}{|c|}{ Descrição das etapas } \\
\hline 1. Cortar a parte de baixo da garrafa de $600 \mathrm{~mL}$, \\
retirando seu fundo; \\
2. Inverter a garrafa, posicionando o gargalo para \\
baixo. Para representar as camadas filtrantes, \\
preenchê-la com os materiais na seguinte ordem: \\
algodão, pedras, areia fina, carvão moído, \\
novamente areia fina e areia grossa.
\end{tabular}

Fonte: Elaborado pelos autores (2021).

O Quadro 4 mostra o terceiro experimento, de filtração, que utiliza a água que foi captada na bacia hidrográfica e passou pelos processos de floculação e decantação. Nesse processo, a gravidade atua novamente, fazendo com que a água passe por todas as camadas, de cima para baixo, levando em conta a diferença de potencial gravitacional. Os poros das camadas vão diminuindo seu tamanho também de cima para baixo, retendo as impurezas que possuem diferentes tamanhos. Destaca-se que o experimento feito nesta ordem representa o filtro existente em uma ETA, que possuem pedras de diferentes diâmetros e areias de diferentes granulometrias para filtrar sujeiras grossas e finas, assim como o carvão para adsorver 
compostos voláteis responsáveis pelo cheiro e gosto da água. A seguir, descreve-se o planejamento e a execução das atividades que aconteceram na visitação à ETA.

\subsection{A visitação à ETA}

Após agendamento por telefone e confirmação de transporte, as duas turmas de $1^{\circ}$ Ano do Ensino Médio foram recepcionadas, em dias diferentes, no pátio da ETA. A visita dividiuse em seis estações e durou duas horas:

- $1^{a}$ Estação - Entrada na ETA: O objetivo nesta estação era dialogar sobre conteúdos gerais relacionados à água e à realidade municipal. Inicialmente, os alunos conheceram algumas regras para a visitação e em seguida foram questionados se já tinham realizado uma visita na ETA. Nessa estação, todos puderam conversar sobre alguns problemas encontrados no município, como a qualidade e quantidade de água existentes nos arroios (córregos) e as indisponibilidades de abastecimento. O município conta com três barragens, mas em períodos de seca, recorre ao racionamento. A guia da visita (autora 1) informou que nas barragens existem vários microrganismos, além de peixes e plantas, justificando a importância do tratamento da água.

- $2^{\text {a }}$ Estação - Imagens dos cursos d'água e mananciais: O objetivo desta estação era mostrar como a gravidade atua sobre os cursos d'água, a partir de imagens de satélite das barragens municipais e da ETA. Debateu-se suas localizações, a distância entre eles, a forma como a água é acumulada e sua chegada na ETA.

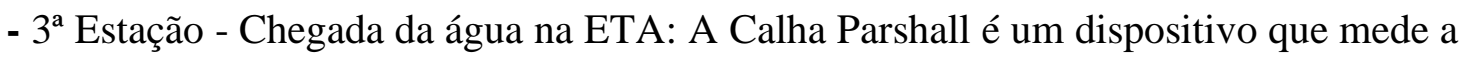
vazão em canais abertos de líquidos fluindo por gravidade. Geralmente, uma ETA a utiliza para medir a entrada e saída de água, bem como a etapa de coagulação das impurezas. Essa estação teve como objetivo esclarecer sobre a importância do tratamento e a quantidade de água que é tratada. Os alunos visualizaram uma amostra da barragem que chegou na estação e receberam informações sobre a presença de microrganismos contidos em uma gota de água, que podem provocar uma série de doenças no organismo. Os estudantes foram convidados a ir até a calha e ouvir a chegada da água e visualizar o fluxo em litros por segundo (L/s). Os discentes também foram informados sobre a adição do floculante sulfato de alumínio $\left(\mathrm{Al}_{2} \mathrm{SO}_{4}\right)$, que tem como função reagir com a água e outros sais, formando hidróxido de alumínio $\left(\mathrm{Al}(\mathrm{OH})_{3}\right)_{\text {. Este, }}$ através de interações eletrostáticas com outros sais e com as partículas de sujeiras carregadas eletrostaticamente, forma os flocos.

- $4^{\text {a }}$ Estação - Tanques de tratamento: O objetivo desta estação foi abordar os conceitos científicos selecionados para estudo durante a visitação. Os visitantes conheceram a planta da ETA e passaram pelo floculador, decantador e filtro. A guia de visitação perguntou se após todas essas etapas, a água já podia ser considerada potável. Em seguida, explicou que ainda não há garantias de retirada total dos microrganismos, sendo necessária a adição de outros compostos. O primeiro é o cloro, no processo denominado cloração, que impede a contaminação da água por bactérias. Apresentou ainda, a portaria do Ministério da Saúde 2.914/2011, que indica a necessidade de adição de flúor. Após essas etapas, a água tratada vai para um reservatório e passa a ser distribuída para a população.

- 5 Estação - Pátio ETA: O objetivo desta estação era abordar de forma contextualizada o consumo populacional e a influência do tratamento para melhorar a qualidade da água consumida pela população. Foi possível conhecer a primeira ETA da cidade e as histórias sobre essa primeira fonte de abastecimento.

- $6^{a}$ Estação - Sala do CEA: Nesta estação foram realizados os experimentos em microescala. Os alunos puderam explorar, na reprodução em escala menor, os conhecimentos 
abordados em toda a visita, desde a captação da água, até o seu tratamento. Antes de encerrar as atividades da última estação, ressaltou-se que após a reprodução em microescala, não se poderia afirmar que a água já está potável, pois não houve adição de cloro e flúor. Os estudantes foram incentivados a combater o desperdício de água, divulgando as informações obtidas na visitação.

É possível perceber que o planejamento de cada estação esteve muito alinhado às informações que pretendiam ser discutidas com os estudantes. Cada nova informação tinha relação com as anteriores e era apresentada de forma contextualizada com a realidade do município e com a vida dos sujeitos.

\section{Resultados e percepções sobre o conhecimento dos alunos participantes}

\subsection{Sensibilização inicial e aplicação do pré-teste}

Antes da visitação à ETA a pesquisadora compareceu nas duas escolas para realizar uma sensibilização inicial e aplicar o pré-teste. Nove alunos da turma da E1 estiveram presentes nesse dia, de um total de 22 que geralmente frequentavam as aulas. Estes demonstraram ter conhecimento sobre a importância da água para a vida do planeta e a necessidade de tratamento antes dela ser consumida. Dentre alguns apontamentos feitos por eles, estavam a contaminação em grande parte da água doce do planeta e dicas para sua economia. No dia em que a pesquisadora compareceu na E2, a turma estava com 27 discentes presentes. Da mesma forma que os estudantes da E1, eles também demonstraram conhecer a importância da água e de seu tratamento. Citaram a contaminação da água doce, inclusive a proveniente dos arroios da cidade. Não conheciam muito sobre a distribuição da água, mas um dos alunos sugeriu que a força que leva a água até a ETA poderia ser a gravidade. Além de terem manifestado conhecimentos sobre sua economia, realizaram perguntas sobre alguns problemas referentes à qualidade, tais como a presença de ferro, manganês, e a relação desses elementos com a coloração escura.

\subsection{Visita à ETA e experimentação}

No dia da visitação à ETA, 20 alunos da turma da E1 compareceram. A maior parte deles conhecia apenas o processo de filtração. Da mesma forma, vários não conheciam os arroios da cidade, entretanto, conseguiram identificar que existe uma força da natureza que contribui para o transporte da água das barragens até a ETA, já que estas estão em um local mais elevado. Não conseguiram dissertar sobre a filtração natural no solo poroso, não identificaram a floculação como um tipo de reação química, mas identificaram que tanto na filtração como na decantação existe a ação da gravidade para que esses processos aconteçam. A turma da E2 se fez presente na ETA com 11 alunos, que manifestaram desconhecimento sobre as barragens do município, mas que argumentaram de forma correta a respeito da ação da gravidade sobre os flocos de sujeira formados na floculação e precipitados na decantação. Falaram sobre a importância do tratamento da água para a qualidade de vida da população e conseguiram relacionar os conhecimentos em macroescala da visita com os conhecimentos em microescala dos experimentos. Quando questionados sobre reação química, uma parcela dos estudantes comentou que já tinham ouvido falar, mas não sabiam defini-la.

\subsection{Pós-teste (problematização)}


Da mesma forma como quando foi realizado o pré-teste, a pesquisadora visitou as escolas E1 e E2 para aplicar o pós-teste. Na turma da E1, ela obteve 21 respostas no questionário. Porém, para comparação dos resultados, apenas as respostas dos nove estudantes que já haviam preenchido o pré-teste foram consideradas. Nesse último encontro, os discentes ratificaram a importância dos processos envolvidos no tratamento da água, dando ênfase para a floculação, filtração e gravidade, classificando-os corretamente como processos físicos e químicos. Também ficou claro para os discentes que o tratamento possui custo elevado e que eles devem mudar seu comportamento com relação ao uso da água. A turma da E2 teve 24 presentes e alguns deles disseram que não tinham muitas lembranças sobre o que viram na ETA. De todos, 17 já haviam respondido ao pré-teste, logo, esse foi o total de questionários considerados.

Com as informações de ambos os questionários (pré-teste e pós-teste), realizou-se uma análise comparativa, verificando se houve uma evolução com relação à aprendizagem dos conceitos e às atitudes assumidas pelos alunos. Foram selecionadas para análise as 10 últimas questões, apresentadas no Quadro 5, uma vez que as quatro primeiras eram apenas para identificação dos respondentes. As 10 perguntas selecionadas estavam em ambos os questionários e versavam sobre o ensino dos conceitos científicos e a conscientização sobre o tratamento.

Quadro 5 - Questões analisadas

\begin{tabular}{|c|l|}
\hline $\mathbf{N}^{\mathbf{0}}$ & \multicolumn{1}{c|}{ Questão } \\
\hline 5 & $\begin{array}{l}\text { Você já ouviu falar em tratamento da água? Se você responder sim, o que é tratamento } \\
\text { de água para você? }\end{array}$ \\
\hline 6 & $\begin{array}{l}\text { A água para ser tratada passa por diferentes etapas. Cite as etapas do tratamento da } \\
\text { água que você conhece ou já ouviu falar }\end{array}$ \\
\hline 7 & Cite um exemplo de filtração que acontece na natureza \\
\hline 8 & Como ocorre a filtração? \\
\hline 9 & Como a água armazenada na caixa da água chega na torneira da sua casa? \\
\hline 10 & O que é decantação? \\
\hline 11 & Cite um exemplo de decantação que você conhece \\
\hline 12 & $\begin{array}{l}\text { O que ocorre quando uma fruta estraga, quando alguma coisa enferruja, quando algo } \\
\text { fica cheirando mal, ou durante a fermentação da massa do pão? }\end{array}$ \\
\hline 13 & O que é reação química para você? \\
\hline 14 & Na etapa de floculação o que acontece? \\
\hline
\end{tabular}

Fonte: Elaborado pelos autores (2021).

As respostas dos alunos referentes às questões apresentadas acima foram categorizadas em adequadas (AD), inadequadas (IN) e em branco (EB). Respostas adequadas foram aquelas que se aproximaram dos conceitos científicos definidos anteriormente no referencial teórico. Respostas inadequadas, aquelas que não condiziam com os conceitos científicos escolhidos. Em branco, questões que os sujeitos não responderam. Para não identificar e expor os alunos participantes, estes foram nomeados por letras do alfabeto.

A questão 5 buscava avaliar se os alunos tinham conhecimento sobre a existência de um tratamento de água. $\mathrm{Na} \mathrm{E} 1$, os nove alunos participantes responderam adequadamente o préteste, demonstrando saber da existência e necessidade do tratamento, e sete alunos responderam adequadamente o pós-teste. Já na E2, os 17 alunos participantes responderam adequadamente o pré-teste e apenas 10 responderam de forma adequada ao pós-teste. Essa diminuição pode 
estar vinculada à falta de empenho em responder, no dia da aplicação do pós-teste, por se tratar de uma questão aberta.

A questão 6 teve a intenção de saber se os alunos tinham conhecimento sobre as etapas do tratamento da água. $\mathrm{Na} \mathrm{E} 1$, nenhum aluno respondeu adequadamente o pré-teste e todos os nove alunos responderam adequadamente o pós-teste. Com relação à E2, quatro dos 17 alunos responderam adequadamente o pré-teste, e durante o pós-teste, sete alunos responderam de forma adequada, evidenciando uma melhora nos resultados com o acréscimo de três alunos.

A questão 7 buscou identificar se os alunos conheciam a técnica de filtração. Um aluno na E1 respondeu adequadamente o pré-teste, exemplificando corretamente onde ocorre a filtração na natureza. Depois da visitação, sete alunos de um total de nove responderam adequadamente, sinalizando um resultado muito positivo. Na E2, assim como na E1, apenas um aluno respondeu adequadamente o pré-teste, enquanto no pós-teste, seis alunos de um total de 17 responderam adequadamente. Não é possível evidenciar um grande resultado nessa escola, mas o acréscimo de cinco respostas corretas também é considerado positivo.

A questão 8 buscava saber se os alunos sabiam como ocorre a filtração, em específico, a força responsável para que ela ocorra. Assim como na questão anterior, a E1 teve apenas uma resposta adequada no pré-teste, mas no pós-teste, esse total subiu para seis. Em relação à E2, foram obtidas duas respostas adequadas no pré-teste, e no pós-teste, oito adequadas.

A questão 9 queria identificar se os alunos tinham conhecimento sobre como a água sai da caixa d'água e chega à torneira de suas casas. As alternativas apresentadas foram: Por bombeamento; Manualmente; Pela ação da natureza; ou Não tenho ideia. A resposta adequada seria a opção "Pela ação da natureza", no entanto, nenhum aluno da E1 no pré-teste assinalou corretamente, sendo que oito apostaram na opção "Por bombeamento" e um assinalou "Não tenho ideia". No pós-teste, oito alunos seguiram apostando na opção "Por bombeamento" e um assinalou corretamente "Pela ação da natureza". Com relação à E2, no pré-teste, 15 alunos responderam "Por bombeamento" e dois "Não tenho ideia". Já no pós-teste, 15 alunos seguiram marcando "Por bombeamento" e dois corretamente "Pela ação da natureza". Essa questão evidencia a necessidade de reforçar diálogos nesse tópico para novas aplicações dessa proposta.

A questão 10 objetivou saber se os alunos conheciam o processo de decantação. Nenhum aluno da E1 respondeu adequadamente ao pré-teste, mas depois da atividade, três dos nove alunos responderam adequadamente. $\mathrm{Na}$ aplicação do pré-teste na $\mathrm{E} 2$, apenas dois responderam de maneira adequada, e no pós-teste, atingiu-se quatro respostas adequadas.

A questão 11 solicitava alguns exemplos de decantação, e tanto no pré-teste, como no pós-teste, nenhum aluno da E1 conseguiu responder. Já na E2, um aluno respondeu de maneira adequada o pré-teste e três alunos o pós-teste. Destacam-se dois alunos da E2: o aluno G respondeu que não sabia no pré-teste e no pós-teste respondeu adequadamente; já o aluno F não respondeu no pré-teste e no pós-teste respondeu adequadamente.

A questão 12 pretendia identificar conhecimentos dos alunos sobre o reconhecimento de alguns fatores que indicam a ocorrência de reações químicas. A pergunta apresentava alternativas: Reação química; Nada acontece; Não sei; ou As coisas estragam. A resposta adequada seria "Reação química", marcada por todos os nove alunos da E1, em ambos os questionários. Na E2, com relação ao pré-teste, 13 dos 17 alunos responderam de forma adequada, dois responderam que não sabiam e um respondeu que nada acontecia. Já no pósteste, foram obtidas 16 respostas adequadas e um aluno respondeu que nada acontecia.

A questão 13 buscou saber se os alunos conheciam o conceito de reação química. Muitos confundiram esse conceito com o de transformação física, uma vez que no pré-teste da E1, 
apenas dois responderam adequadamente, e no pós-teste, cinco. Esse argumento se ratifica com as respostas da E2, pois no pré-teste oito alunos acertaram, enquanto no pós-teste, apenas seis.

Por fim, a questão 14 objetivava saber se os alunos conheciam o processo de floculação. No pré-teste da E1, três alunos responderam de forma adequada, cinco misturaram conceitos ao abordar a reação química como um processo de decantação de flocos e um aluno não sabia. No pós-teste dessa escola, todos os nove alunos responderam adequadamente. Com relação à E2, no pré-teste, apenas dois alunos responderam adequadamente, destacando que ocorre reação química na formação de flocos. Cinco alunos confundiram com o processo de decantação e um respondeu que não sabia. Depois da visitação, no pós-teste, 13 dos 17 alunos responderam adequadamente, enquanto dois ainda confundiram com decantação e dois não sabiam. Os Gráficos 1 e 2 apresentam as respostas adequadas da E1 e da E2.

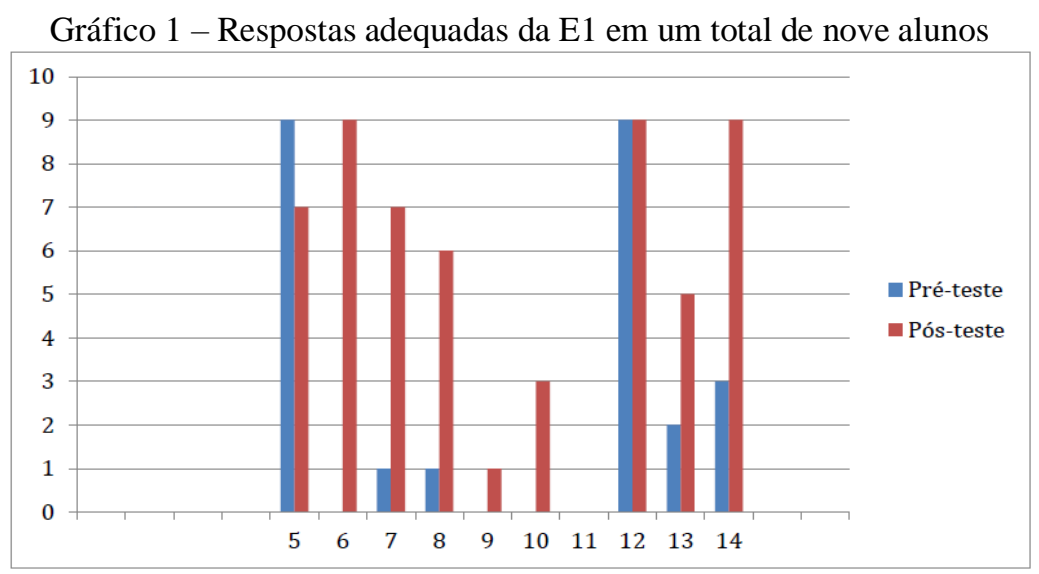

Fonte: Elaborado pelos autores (2021).

Gráfico 2 - Respostas adequadas da E2 em um total de 17 alunos

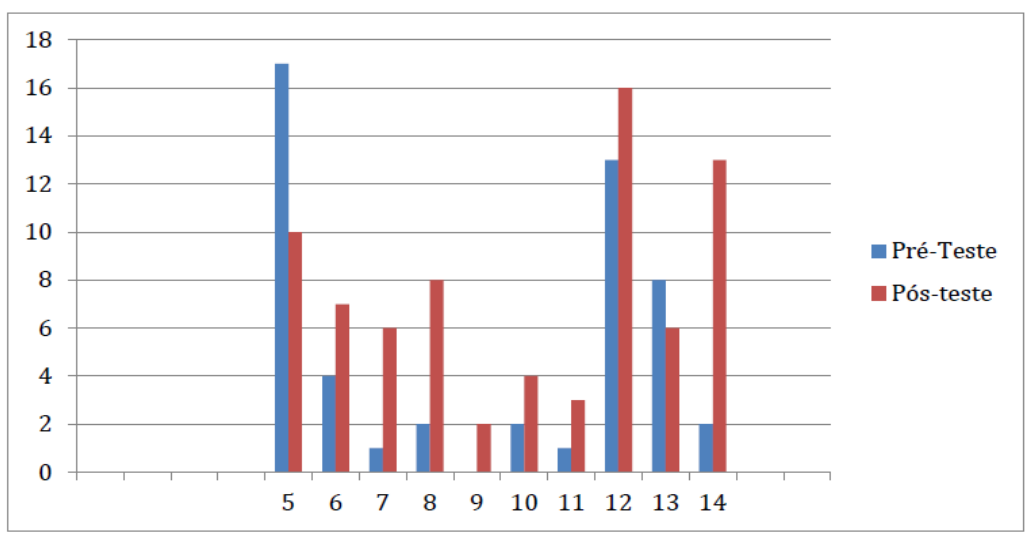

Fonte: Elaborado pelos autores (2021).

Analisando os dados dos gráficos, é possível verificar que de maneira geral, houve um aumento no número de respostas adequadas na maioria das questões, quando comparados o préteste e o pós-teste. Houve redução de respostas adequadas apenas na questão de número cinco e aumento nas questões de número seis (tratamento da água), sete a 11 (separação de misturas e gravidade) e 12 a 14 (reação química e separação de misturas). Somando as respostas adequadas das duas escolas, se observa que a questão de número 14 foi a que mais apresentou melhora nas respostas, obtendo um valor acima de $65 \%$ em ganho de acertos. Analisando as 

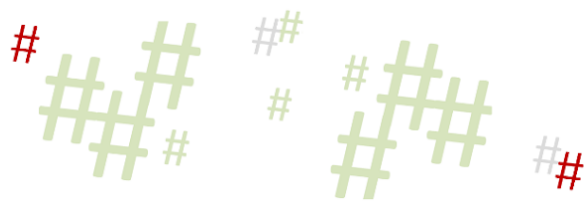

questões relacionadas aos conceitos científicos, se percebe que: nas questões sobre gravidade houve um aumento de quase $25 \%$ nas respostas corretas; nas questões sobre reação química o aumento foi de quase $27 \%$; sobre filtração o ganho atingiu $42 \%$; sobre decantação o ganho foi de 19\%; e sobre floculação se atingiu 65\% de respostas adequadas após a visitação à ETA e aplicação da experimentação demonstrativa.

Todas as questões que abordavam os conceitos científicos conseguiram aumentar a taxa positiva de respostas. Por consequência, a maioria destas estava relacionada à conscientização dos estudantes, indicando assim, um aumento positivo nesse aspecto. Estes resultados conferem com o que foi concluído por Ishiba et al. (2013), que após a visita técnica à ETA, houve um progresso com relação à aprendizagem dos conceitos de processos físicos e químicos. Desta maneira, as atividades aqui propostas contribuíram para a formalização de conceitos científicos e conscientização dos estudantes.

\section{Considerações finais}

São esboçadas a seguir algumas considerações sobre os objetivos da pesquisa, de avaliar a estratégia de utilização da experimentação demonstrativa em microescala em uma ETA, visando ampliar o conhecimento dos alunos no que diz respeito à aprendizagem de conceitos científicos e à mudanças de atitudes. Os resultados obtidos demonstraram que as atividades atingiram seus objetivos, levando os autores a considerar que a atividade didática pode ser utilizada por professores para desenvolver conteúdos relacionados a esses conceitos.

A única questão em que houve redução de respostas adequadas, relacionada aos cuidados com a qualidade da água, sinaliza que, apesar das demais terem obtido resultados melhores, ainda é preciso intensificar diálogos sobre a mudança de atitude para futuras aplicações. Com relação à aplicação da proposta na Educação Básica, se destacam como pontos positivos o interesse na visitação à ETA e as possibilidades de contextualizar o EC. Entre os pontos negativos citamos o pouco tempo de visitação, algumas dificuldades quanto ao transporte e o pouco interesse dos alunos em responder algumas questões abertas.

Com relação à aplicação da ação pedagógica, considera-se que houve contribuições positivas para o entendimento de que é possível a utilização de experimentos em ENFE para o EC, desde que seja de maneira complementar ao ensino realizado na escola. A visitação na ETA pode ser organizada por qualquer professor, desde que a estação tenha um monitor designado para este tipo de atividade e que o professor realize um bom planejamento, tornando a visitação atrativa e enriquecedora. Com base no referencial teórico, pode-se concluir que os ENFE não devem ser vistos como uma proposta contrária ou alternativa à educação formal, mas sim, um complemento, tendo em vista que pressupõem intencionalidades bem definidas no que se refere à organização e estruturação das atividades.

Por fim, demonstrar o tratamento da água em microescala facilitou o entendimento das etapas pelas quais a água passa antes de se tornar potável. Como sugestão, indica-se a prática da experimentação como rotina para os visitantes das ETA. Constatou-se a pouca existência de artigos específicos sobre o tema, uma vez que ao buscarmos por produções que associam o EC aos ENFE, nenhum artigo envolvendo visitação à ETA foi encontrado. Os artigos que mais se aproximaram, continham propostas de construção de algumas etapas de tratamento, no formato de oficinas ou em sala de aula. Além disso, nada foi encontrado sobre a utilização de experimentação nas ETA. Devido às limitações já comentadas, é importante que seja realizado o planejamento das atividades para que as barreiras entre os EFE e ENFE sejam vencidas e a qualidade da aprendizagem seja alcançada em ambos os espaços. 


\section{Referências}

BARBOSA, D. F. S.; ROCHA, C. J. T.; MALHEIRO, J. M. S. As perguntas do professor monitor na experimentação investigativa em um clube de ciências: classificações e organização. Research, Society and Development, Vargem Grande Paulista, v. 8, n. 4, p. 121, 2019. Disponível em https://dialnet.unirioja.es/servlet/articulo?codigo=7164698. Acesso em:18 jan. 2021

BERTAN, F. A. B. et al. A bioquímica e a biotecnologia através de oficinas de experimentação em espaços não formais de aprendizagem. In: SIMPÓSIO DE BIOQUÍMICA E BIOTECNOLOGIA, 5., 2015, Londrina. Anais [...]. Londrina, 2015. Disponível em http://pdf.blucher.com.br.s3-sa-east1.amazonaws.com/biochemistryproceedings/vsimbbtec/22411.pdf. Acesso em:16 jan. 2021.

CERVO, A. L.; BERVIAN, P. A.; SILVA, R. Metodologia Científica. 6. ed. São Paulo: Pearson Prentice Hall, 2007.

CLEOPHAS, M. G. Ensino por investigação: concepções dos alunos de Licenciatura em Ciências da Natureza acerca da importância de atividades investigativas em espaços não formais. Revista Linhas, Florianópolis, v. 17, n. 34, p. 266-298, 2016. Disponível em https://www.revistas.udesc.br/index.php/linhas/article/view/1984723817342016266/pdf_132. Acesso em:16 jan. 2021.

COMPANHIA RIOGRANDENSE DE SANEAMENTO - CORSAN. Tratamento de Água. 2021. Disponível em https://www.corsan.com.br/tratamentodeagua. Acesso em: 22 jan. 2021.

DI BERNARDO, L.; PAZ, L. P. S. Seleção de tecnologias de Tratamento de Água. 1. ed. v. 1. São Carlos: LDIBE, 2008.

FOLEIS, B. L. M. et al. O tratamento de água no contexto do ensino de química. Sinergia, São Paulo, v. 17, n. 1, p. 70-73, 2016. Disponível em https://ojs.ifsp.edu.br/index.php/sinergia/article/view/80. Acesso em:18 jan. 2021.

FONSECA, M. R. M. Química: ensino médio. Manual do Professor. 2. ed. São Paulo: Ática, 2016.

FRANCISCO JUNIOR, W. E.; FERREIRA, L. H.; HARTWIG, D. R. Experimentação problematizadora: fundamentos teóricos e práticos para a aplicação em salas de aula de ciências. Química Nova na Escola, n. 30, p. 34-41, 2008. Disponível em http://qnesc.sbq.org.br/online/qnesc30/07-PEQ-4708.pdf. Acesso em:15 jan. 2021.

GALIAZZI, M. C. et al. Objetivos das atividades experimentais no ensino médio: a pesquisa coletiva como modo de formação de professores de ciências. Ciência \& Educação, Bauru, v. 7, n. 2, p. 249-263, 2001. Disponível em http://www.scielo.br/pdf/ciedu/v7n2/08.pdf. Acesso em:14 jan. 2021.

GASPAR, A.; MONTEIRO, I. C. C. Atividades experimentais de demonstrações em sala de aula: uma análise segundo o referencial da teoria de Vygotsky. Investigações em Ensino de Ciências, Porto Alegre, v. 10, n. 2, p. 227-254, 2005. Disponível em https://www.if.ufrgs.br/cref/ojs/index.php/ienci/article/view/518/315. Acesso em:15 jan. 2021. 
HALLIDAY, D.; RESNICK, R.; WALKER, J. Fundamentos de Física: gravitação, ondas e termodinâmica. 10. ed., v. 2. Rio de Janeiro: LTC, 2016.

HARTMANN, A. M. O Pavilhão da Ciência: a participação de escolas como expositoras na Semana Nacional de Ciência e Tecnologia. Tese (Doutorado em Educação), Universidade de Brasília. Brasília, 2012. Disponível em: https://repositorio.unb.br/handle/10482/11254. Acesso em: 24 maio 2021.

ISHIBA, L. F. L. et al. Oficina Temática com visita a uma ETA. In: ENCONTRO PAULISTA DE PESQUISA EM ENSINO DE QUÍMICA, 2013, Santo André. Anais [...]. Santo André, 2013. Disponível em http://eventos.ufabc.edu.br/eppeq2013/anais/resumos/59.pdf. Acesso em: 01 fev. 2021.

MACEDO, J. M.; PENHA, M. R. Desmistificando a química: investigação das definições dos estudantes do IFRO sobre o real conceito das reações químicas. Educação por Escrito, Porto Alegre, v. 5, n. 1, p. 51-67, 2014. Disponível em

https://revistaseletronicas.pucrs.br/ojs/index.php/porescrito/article/view/15818/11500. Acesso em:19 jan. 2021.

MARQUES, J. B. V.; FREITAS, D. Fatores de caracterização da educação não formal: uma revisão de literatura. Educação e Pesquisa, São Paulo, v. 43, n. 4, p. 1087-1110, 2017.

Disponível em http://www.scielo.br/pdf/ep/v43n4/1517-9702-ep-S1517-

9702201701151678.pdf. Acesso em:13 jan. 2021.

MÁXIMO, A. R. L.; ALVARENGA, B. A. Física: Coleção de olho no mundo do trabalho A Física no campo da ciência. 1. ed. São Paulo: Scipione, 2003.

MENDES, M. P. L. O conceito de reação química no nível médio: história, transposição didática e ensino. Dissertação (Mestrado em Ensino, Filosofia e História das Ciências), Universidade Federal da Bahia, Salvador, 2011. Disponível em encurtador.com.br/irIR2. Acesso em:19 jan. 2021.

MOREIRA, M. A. Metodologias de Pesquisa em Ensino. 1. ed. Porto Alegre: LF Editorial, 2011.

PERTICARRARI, A.; TRIGO, F. R.; BARBIERI, M. R. A contribuição de atividades em espaços não formais para a aprendizagem de botânica de alunos do ensino básico. Ciência em Tela, Rio de Janeiro, v. 4, n. 1, p. 1-12, 2011. Disponível em http://www.cienciaemtela.nutes.ufrj.br/artigos/0111_perticarrari.pdf. Acesso em:18 jan. 2021.

PINTO, L. T.; FIGUEIREDO, V. A. O ensino de ciências e os espaços não formais de ensino: um estudo sobre o ensino de ciências no município de Duque de Caxias/RJ. In: SIMPÓSIO NACIONAL DE ENSINO DE CIÊNCIA E TECNOLOGIA, 2., 2010, Ponta Grossa. Anais [...]. Ponta Grossa, 2010. Disponível em http://www.sinect.com.br/anais2010/artigos/EC/179.pdf. Acesso em:16 jan. 2021.

PORTO, M. G. C. et al. O ensino de Química e Física em espaços não-formais. In: ENCONTRO NACIONAL DE PESQUISA EM EDUCAÇÃO EM CIÊNCIAS, 8., 2011, Campinas. Anais [...]. Campinas: ABRAPEC, 2011. Disponível em http://abrapecnet.org.br/atas_enpec/viiienpec/resumos/R1170-2.pdf. Acesso em:12 jan. 2021. 
ROCHA, C. J. T.; MALHEIRO, J. M. S. Interações dialógicas na experimentação investigativa em um clube de ciências: proposição de instrumento de análise metacognitivo. Amazônia - Revista de Educação em Ciências e Matemáticas, Belém, v. 14, n. 29, p. 193 207, 2018. Disponível em https://periodicos.ufpa.br/index.php/revistaamazonia/article/view/5476/4777. Acesso em:18 jan. 2021.

SALESSE, A. M. T. A experimentação no ensino de química: importância das aulas práticas no processo de ensino aprendizagem. Monografia (Especialização em Educação) Universidade Tecnológica Federal do Paraná, Medianeira, 2012. Disponível em encurtador.com.br/ktAQS. Acesso em:15 jan. 2021.

SANTOS, W. L. P.; MALDANER, O. A. Ensino de química em foco. 1. ed. Ijuí: Unijuí, 2011.

SANTOS, H. F.; AMARAL, C. L. C. Experimentação investigativa: aprendizagem de conceitos químicos através da montagem parcial de uma estação de tratamento de água. Scientia Naturalis, Rio Branco, v. 1, n. 2, p. 281-296, 2019. Disponível em https://periodicos.ufac.br/index.php/SciNat/article/view/2510. Acesso em:18 jan. 2021.

SANTOS, L. R.; MENEZES, J. A. A experimentação no ensino de química: principais abordagens, problemas e desafios. Pesquiseduca, Santos, v.12, n. 26, p. 180-207, 2020. Disponível em https://periodicos.unisantos.br/pesquiseduca/article/view/940/pdf. Acesso em: 14 jan. 2021.

SILVA, O. C.; VASCONCELOS, T. N. H. Tratamento de água para consumo humano: atividades práticas de ensino de ciências e química com emprego de moringa oleifera LAM. Revista de Produção Discente em Educação Matemática, São Paulo, v. 2, n. 2, p. 41-48, 2013. Disponível em https://revistas.pucsp.br/index.php/pdemat/article/view/17116/12710. Acesso em:14 jan. 2021.

VIEIRA, V.; BIANCONI, M. L.; DIAS, M. Espaços não-formais de ensino e o currículo de ciências. Ciência e Cultura, Campinas, v. 57, n. 4, p. 21-23, 2005. Disponível em http://cienciaecultura.bvs.br/pdf/cic/v57n4/a14v57n4.pdf. Acesso em:14 jan. 2021.

VIVEIRO, A. A.; DINIZ, R. E. S. Atividades de campo no ensino das ciências e na educação ambiental: refletindo sobre as potencialidades desta estratégia na prática escolar. Ciência em Tela, Rio de Janeiro, v. 2, n. 1, p. 1-12, 2009. Disponível em http://www.cienciaemtela.nutes.ufrj.br/artigos/0109viveiro.pdf. Acesso em:11 out. 2021.

ZÔMPERO, A. F.; PASSOS, A. Q.; CARVALHO, L. M. A docência e as atividades de experimentação no ensino de ciências nas séries iniciais do ensino fundamental. Experiências em Ensino de Ciências, v. 7, n. 1, p. 43-54, 2012. Disponível em https://if.ufmt.br/eenci/artigos/Artigo_ID174/v7_n1_a2012.pdf. Acesso em:15 jan. 2021.

Recebido em junho de 2021.

Aprovado em outubro de 2021. 